\title{
Turbulence Characteristics of Flow Field around a Cylindrical Obstacle Placed in a Trapezoidal Channel
}

\author{
Ömer Köse* \\ Department of Civil Engineering, Aksaray University, 68100 Aksaray Turkey
}

Received: 18 April 2017

Accepted: 19 August 2017

\begin{abstract}
This paper describes measurements of the turbulence surrounding a vertical cylinder in a steady flow. The approximate size of circulations and eddies produced by a cylindrical obstacle subject to steady flow in a trapezoidal channel are investigated. A four-component high-sampling frequency acoustic doppler velocimeter (ADV) was used to collect flow data, which were filtered using effective filtering algorithms before being processed. Because the turbulence is three dimensional, calculations were performed for all three directions. The energy distribution and dependence of the fluctuating velocities were determined and interpreted using an autocorrelation function and spectral analysis. Important turbulence statistics were calculated, including Reynolds stresses, integral time scales, and integral length scales. For representative points, the approximate size of the turbulent eddy was calculated. A spectral density function was generated and analyzed. The results show that highly coherent and dependent structures are visible in the wake vortices region for each axis..
\end{abstract}

Keywords: turbulence statistics, spectral analysis, autocorrelation

\section{Introduction}

Turbulence plays an important role such as nutrient transfer, pollutant dispersion, and sediment transport, which is also themostcommon, important, and complicated type of fluid motion. Turbulence causes irregular, chaotic, and random velocity and pressure fluctuations at very high frequencies, and it is a property of any rotational, dissipative, and diffusive process, which converts kinetic energy to heat by viscosity through vortices. Flows that occur in nature and in laboratory applications are often turbulent. Low Reynolds number flows are only

*e-mail: omerkose@aksaray.edu.tr observed in the laboratory. All flows in rivers and canals are turbulent. Some characteristics of turbulent flow are its irregularity and large Reynolds numbers [1-5]. This paper describes measurements of the turbulence around a vertical circular cylinder placed in a steady flow. The flow around the cylinder is three-dimensional turbulent flow [6-8]. On the front side of the cylinder, down flow develops, which is the principle cause of the horseshoe vortices created by pier and abutment scours in rivers [913]. On the upstream free surface of the cylinder, a bow wave develops. Wake vortex shedding in the downstream region at the rear of the cylinder also occurs. However, most engineering and Eco hydraulic applications are not interested in the solution of the turbulent fluctuations, but rather the flow properties. A number of alternative 


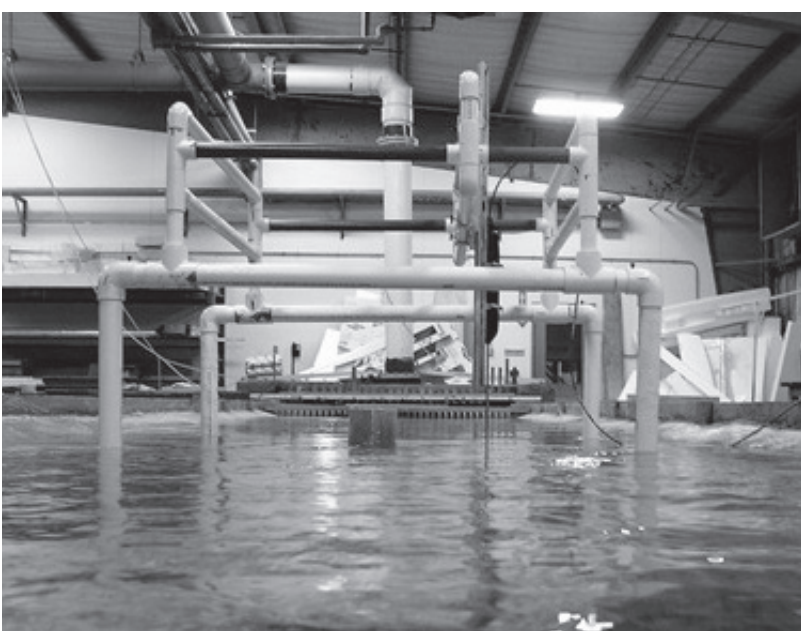

Fig. 1. ADV mounted on a plastic frame that is movable for three axes.

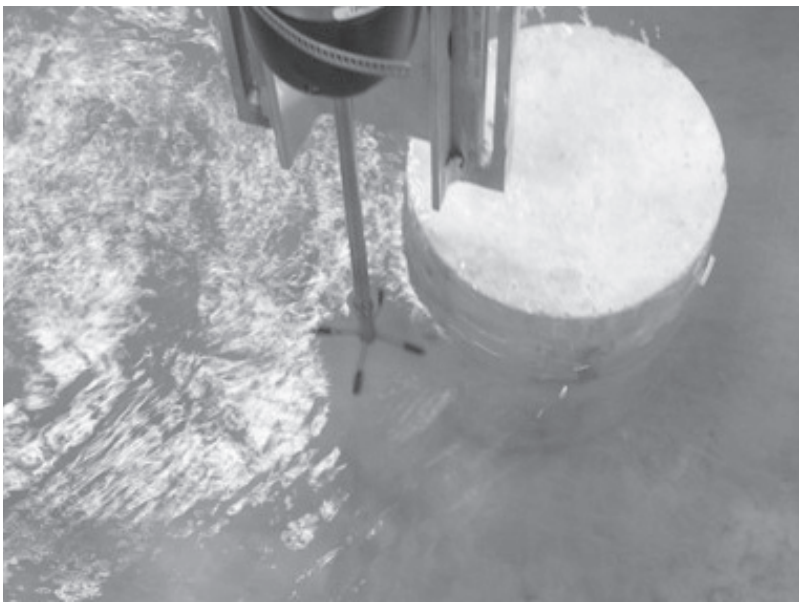

Fig. 2. Recording data around the obstacle. methods to numerical hydrodynamic models for the description of river hydraulics have been developed [14].

This paper describes measurements of turbulence statistics for the flow around a vertical circular cylinder that is placed in a steady flow, the cylinder is considered as a model to simulate a boulder in the riverine environment so the significance of the study arises from presenting a non-numerical approach. A great amount of data for flow close to the cylinder is obtained. The approximate size of coherent structures, distribution of Reynolds stresses for the three velocity components, integral time scales, and integral length scales are calculated, interpreted, and compared with other studies cited in the literature. The power spectral density is analyzed for representative points very close to the cylinder. The aim of the study was to better understand the distribution of turbulence statistics, and size of coherent structures close to the vertical cylinder in the trapezoidal channel.

\section{Materials and Methods}

\section{Experimental Setup}

The experiments were conducted in the trapezoidal channel at the Water Resources Laboratory at the University of Texas at Austin. Figs 1 and 2 show an image of the channel.

A vertical cylinder $15 \mathrm{~cm}$ in diameter and $30 \mathrm{~cm}$ high was placed in the middle of a nearly horizontal trapezoidal channel. The water depth was a constant $23.6 \mathrm{~cm}$. Measurements were taken at 75 data points surrounding the cylindrical obstacle. Fig. 2 shows data being collected near the cylinder. Data was collected using a four-component ADV with a sampling frequency of $100 \mathrm{~Hz}$. The smallest ADV probe was used because it created the least disturbance to the flow. The ADV was

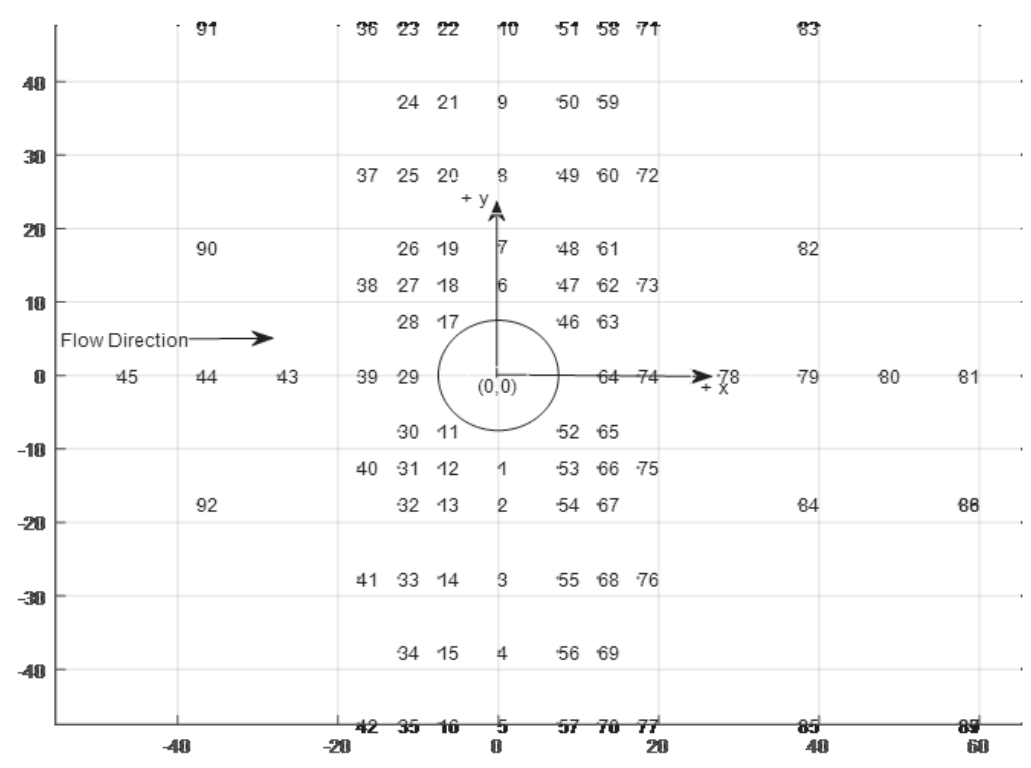

Fig. 3. Settlement of data points. 
Table 1. One-minute average velocities for $\mathrm{x}, \mathrm{y}, \mathrm{z}(\mathrm{cm} / \mathrm{s})$ directions and Reynold stress values $\left(\mathrm{cm}^{2} / \mathrm{s}^{2}\right)$.

\begin{tabular}{|c|c|c|c|c|c|c|}
\hline Point number & $\mathrm{u}$ & $\mathrm{v}$ & $\mathrm{w}$ & u'v' & u’w' & v'w' \\
\hline 1 & 30.180 & -5.666 & -1.655 & 0.640 & -0.190 & 0.140 \\
\hline 2 & 28.819 & -3.644 & -1.307 & -74.530 & 5.520 & -7.560 \\
\hline 3 & 29.722 & -2.591 & -0.436 & -28.810 & 68.670 & -8.180 \\
\hline 4 & 26.271 & -2.905 & -0.510 & 8.100 & -0.610 & -9.830 \\
\hline 6 & 31.828 & 2.925 & -0.923 & -0.530 & -0.260 & -0.090 \\
\hline 7 & 30.521 & 2.101 & -0.254 & -0.510 & -0.360 & 0.010 \\
\hline 8 & 30.220 & 0.966 & -0.299 & -0.660 & -0.160 & -0.090 \\
\hline 9 & 31.197 & -0.359 & -0.934 & -0.620 & -0.140 & -0.080 \\
\hline 10 & 31.069 & -0.163 & -0.203 & -0.020 & -0.410 & 0.150 \\
\hline 11 & 23.49 & -10.08 & -1.32 & 0.220 & -0.270 & 0.070 \\
\hline 12 & 25.822 & -6.261 & -0.879 & 0.130 & -0.290 & 0.010 \\
\hline 13 & 17.182 & -4.310 & -0.510 & -14.600 & -0.380 & 0.380 \\
\hline 14 & 22.159 & -3.494 & -1.769 & 7.750 & 18.920 & 0.920 \\
\hline 15 & 26.313 & -2.218 & -0.542 & -0.470 & -0.350 & 0.050 \\
\hline 17 & 20.40 & 10.23 & -1.10 & -0.360 & -3.220 & -0.110 \\
\hline 18 & 25.264 & 6.622 & -0.598 & -0.360 & -0.270 & -0.050 \\
\hline 19 & 26.951 & 3.997 & -0.231 & -0.580 & -0.330 & -0.150 \\
\hline 20 & 28.420 & 1.765 & -0.252 & -0.930 & -0.210 & 0.110 \\
\hline 21 & 28.801 & 0.254 & -0.358 & -1.240 & -0.370 & 0.090 \\
\hline 22 & 29.491 & -0.421 & -0.123 & -0.110 & -0.530 & 0.070 \\
\hline 23 & 29.614 & -0.159 & -0.017 & -0.010 & -0.400 & 0.190 \\
\hline 24 & 29.489 & -0.014 & -0.189 & -0.600 & -10.420 & 0.030 \\
\hline 25 & 28.329 & 1.237 & -0.193 & -0.720 & 0.030 & 0.000 \\
\hline 26 & 25.920 & 3.107 & -0.095 & -0.680 & -0.370 & -0.120 \\
\hline 27 & 23.755 & 4.369 & -0.031 & -0.800 & -0.280 & -0.020 \\
\hline 28 & 20.503 & 4.665 & -0.428 & -0.520 & -0.310 & 0.030 \\
\hline 29 & 16.02 & -0.98 & -1.05 & -0.070 & -0.240 & 0.150 \\
\hline 30 & 21.302 & -5.857 & -0.802 & 0.050 & -0.270 & 0.080 \\
\hline 31 & 24.180 & -5.323 & -0.549 & 0.090 & -0.360 & 0.110 \\
\hline 32 & 25.337 & -3.978 & -0.369 & -0.240 & -0.240 & 0.040 \\
\hline 33 & 25.007 & -2.588 & -0.230 & 19.820 & -74.330 & -5.460 \\
\hline 34 & 25.521 & -3.959 & -0.218 & 5.460 & -0.520 & -0.460 \\
\hline 37 & 27.613 & 1.202 & 0.015 & -0.640 & -0.020 & 0.000 \\
\hline 38 & 23.275 & 2.036 & -0.009 & -0.620 & -0.320 & -0.040 \\
\hline 39 & 19.928 & -0.815 & -0.440 & -0.020 & -0.610 & 0.010 \\
\hline 40 & 23.425 & -3.088 & -0.392 & 0.210 & -0.400 & 0.110 \\
\hline 41 & 25.197 & -2.675 & -0.302 & 10.570 & -1.380 & -1.910 \\
\hline 43 & 22.403 & -0.624 & -0.172 & 0.250 & -0.310 & 0.130 \\
\hline 44 & 22.769 & -0.571 & -0.193 & 0.080 & -0.120 & 0.030 \\
\hline
\end{tabular}


Table 1. Continued.

\begin{tabular}{|c|c|c|c|c|c|c|}
\hline 46 & 14.746 & -4.821 & -3.125 & -69.500 & -22.330 & 12.290 \\
\hline 47 & 32.730 & -2.837 & -0.769 & -0.330 & 0.260 & -0.100 \\
\hline 48 & 31.459 & -0.765 & -0.778 & 0.010 & -0.370 & -0.010 \\
\hline 49 & 30.568 & -0.151 & -0.352 & -0.540 & -0.180 & 0.130 \\
\hline 50 & 31.245 & -0.368 & -0.454 & -0.390 & -0.190 & 0.240 \\
\hline 51 & 31.247 & -0.396 & -0.599 & -0.230 & -0.510 & 0.140 \\
\hline 52 & 30.285 & -0.738 & -2.399 & 13.300 & 1.820 & 1.130 \\
\hline 53 & 31.382 & -2.688 & -2.051 & 0.420 & -0.260 & 0.060 \\
\hline 54 & 29.631 & -2.012 & -1.557 & -0.140 & -0.300 & 0.080 \\
\hline 55 & 28.068 & -0.687 & -1.006 & -53.630 & 8.710 & -11.670 \\
\hline 56 & 23.272 & -1.228 & 0.108 & -5.600 & -58.800 & 1.090 \\
\hline 58 & 30.965 & -0.551 & -0.722 & -0.290 & -0.540 & 0.130 \\
\hline 59 & 31.070 & -0.634 & -0.515 & -0.510 & -0.190 & -0.040 \\
\hline 60 & 30.532 & -0.718 & -0.572 & -0.540 & -0.060 & 0.000 \\
\hline 61 & 30.914 & -2.052 & -0.900 & 0.030 & -0.310 & -0.350 \\
\hline 62 & 31.879 & -3.333 & -0.524 & -0.070 & -0.700 & 0.190 \\
\hline 63 & 15.84 & -3.98 & -1.93 & -58.740 & -15.080 & 10.590 \\
\hline 64 & -2.09 & 0.39 & 0.71 & -5.390 & -7.780 & 0.320 \\
\hline 65 & 27.915 & 1.238 & -2.411 & 23.490 & 5.650 & 2.870 \\
\hline 66 & 30.817 & -0.103 & -1.636 & -0.370 & -0.060 & 0.300 \\
\hline 67 & 29.726 & -0.910 & -1.384 & -0.370 & -0.200 & 0.050 \\
\hline 68 & 28.037 & -0.436 & -1.169 & 2.310 & 3.600 & 0.840 \\
\hline 69 & 11.964 & -0.941 & 3.099 & 2.350 & -142.870 & -0.850 \\
\hline 71 & 31.279 & -7.100 & -0.755 & 6.960 & -0.350 & -2.490 \\
\hline 72 & 30.658 & -0.679 & -1.403 & 0.260 & -0.120 & -0.440 \\
\hline 73 & 29.201 & -5.964 & -1.253 & -6.540 & 1.420 & -3.280 \\
\hline 74 & -5.262 & 0.661 & 1.733 & -6.920 & 4.880 & 8.110 \\
\hline 75 & 30.829 & 0.462 & -1.592 & -0.520 & -0.170 & 0.170 \\
\hline 76 & 27.269 & -0.471 & -0.669 & 1.240 & 0.310 & 0.290 \\
\hline 78 & 4.049 & 1.167 & 3.247 & 26.340 & -3.180 & -7.390 \\
\hline 79 & 10.680 & 2.023 & 1.323 & 31.930 & -4.160 & -6.700 \\
\hline 82 & 26.376 & -4.312 & 0.287 & -3.070 & -0.060 & 1.080 \\
\hline 83 & 31.063 & -2.182 & -0.564 & 10.630 & -0.460 & -4.140 \\
\hline 84 & 27.286 & 1.602 & -0.996 & -0.280 & -0.020 & 0.230 \\
\hline 90 & 24.261 & 0.490 & 0.120 & -0.590 & -0.430 & -0.170 \\
\hline 91 & 29.761 & -3.357 & -0.053 & 0.340 & -0.250 & -0.140 \\
\hline 92 & 23.813 & -1.070 & 0.000 & 3.580 & -25.340 & -1.090 \\
\hline
\end{tabular}

mounted onto a frame that allowed movement in all three directions. The frame legs were plastic, circular, very thin, and streamlined, therefore no interference was observed between them and the ADV probes. A ruler was attached to the frame so the ADV could be positioned to within a millimeter in each direction. The distance from the bed 
of the channel was determined using both the distance sensor of the ADV and a ruler. During the experiments, the data was sampled at a constant $100 \mathrm{~Hz}$ rate. It was observed that when the sampling rate increased, the Doppler noise level and spikes also increased. Based on the work a $1 \mathrm{~min}$ sampling time was chosen for each measurement point.

\section{Experiments}

An analytical coordinate system was established around the cylinder (Fig. 3). For x, y coordinate axes anticlockwise and for $\mathrm{z}$ direction upward is defined as positive. The origin of the coordinate system was located at the center of the cylinder. The experimental arrangement and conditions are shown in detail in Fig. 3. Data were recorded from 76 different points under identical steady flow conditions.

Velocity data for the $\mathrm{x}, \mathrm{y}$, and $\mathrm{z}$ directions as well as Reynolds stress data are listed in Table 1. Because turbulence is a complicated three-dimensional process, velocity data are sampled and recorded at $0.01 \mathrm{~s}$ intervals. A bar over a value indicates that it represents a mean. The turbulent fluctuations of velocity $\mathrm{u}^{\prime}, \mathrm{v}^{\prime}$, and $\mathrm{w}^{\prime}$ in the $\mathrm{x}, \mathrm{y}$, and $\mathrm{z}$ directions, respectively, are defined in Eq. 1:

$$
\mathbf{u}^{\prime}=\mathbf{u}-\overline{\mathbf{u}}, \quad \mathbf{v}^{\prime}=\mathbf{v}-\overline{\mathbf{v}}, \mathbf{w}^{\prime}=\mathbf{w}-\overline{\mathbf{w}}
$$

Effective filtering algorithms are applied to the raw data, and prior to filtering of the ADV data ADV gives two important parameters that are related to the quality of the sampling. These are the signal-to-noise-ratio (SNR) and correlation (COR) parameters. The criterion for SNR is taken as 15 , and the COR criterion applied is $70 \%$ [1516]. To filter the velocity time series for each component, a phase-space filter algorithm [17] is used. This is an effective tool to detect and replace spikes.

\section{Results and Discussion}

Applying Autocorrelation Function, Integral Time, and Length Scales of Turbulence Data

The vector velocity distribution around the cylinder is shown in Fig. 4. The points where the velocity is accelerated are readily apparent.

The autocorrelation function describes the correlation between the consecutive values of the time series. Generally, in the various fields of research it is used to check the time dependence of a series of data, and here it is used to interpret a physical event. Autocorrelation is useful for finding repeating patterns such as the presence of a periodic circulating structure. In this study autocorrelation analysis is applied to detect dependent, coherent structures such as eddies. The autocorrelation behavior of the points very close to the cylinder is investigated and interpreted for the $\mathrm{x}, \mathrm{y}$, and $\mathrm{z}$ velocity components. Using autocorrelograms, the integral time and length scales are calculated for each direction. For a streamwise velocity component the normalized autocorrelation function is:

$$
r_{u u}(\Delta t)=\frac{\overline{u^{\prime}(t) u^{\prime}(t+\Delta t)}}{\overline{u^{\prime 2}}}
$$

Point number 64 is selected for analysis and is located at a wake vortices region, downstream of a and very close to the cylinder. Fig. 5 shows an autocorrelogram of the velocity at point 64 given as $r$ values versus time interval, $(\Delta \mathrm{t})$ with $\Delta \mathrm{t}=0.01 \mathrm{sec}$.

As seen in Fig. 5, the correlograms for the $\mathrm{v}$ and $\mathrm{w}$ components decay abruptly and show a disorganized and uncorrelated random structure. The correlogram for the $\mathrm{u}$ component decays late and shows a dependent

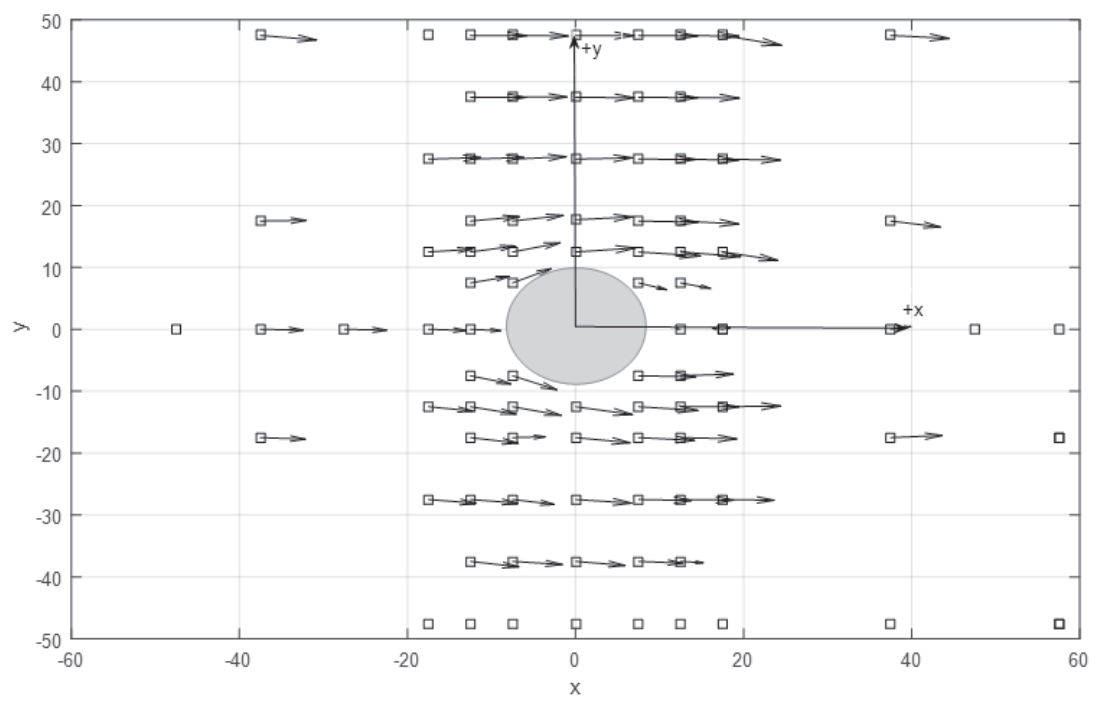

Fig. 4. Vectoral velocity distribution around the cylinder. 


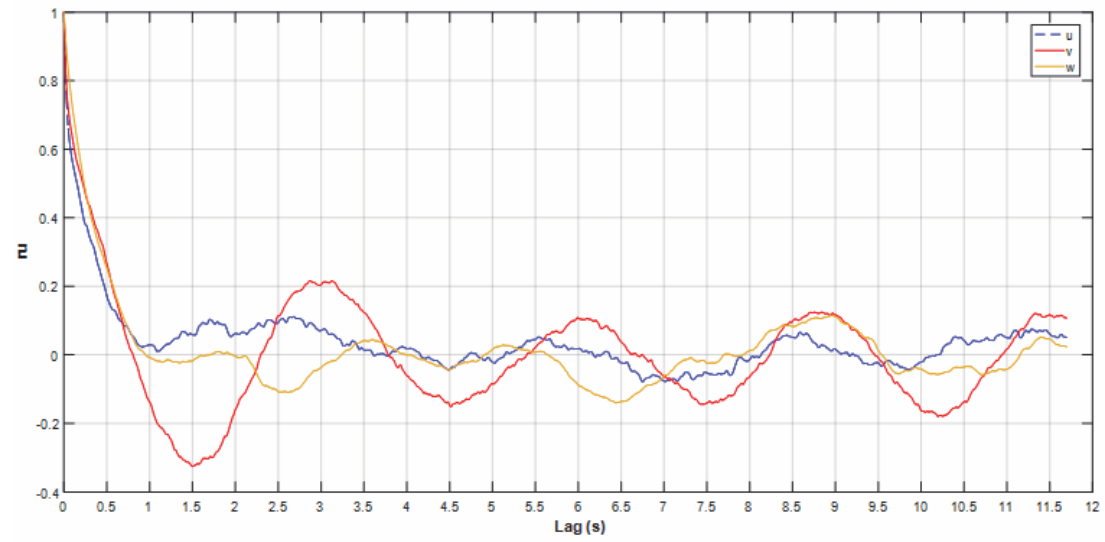

Fig. 5. Autocorrelogram of point 64 for $\mathrm{u}, \mathrm{v}$, and w velocity components.

structure. Using autocorrelation functions for each velocity component, an integral time scale equation (3) for each component can be calculated by integrating the autocorrelation function numerically from zero lag to the first zero crossing using numerical integration. Simpson's rule [18] $\mathrm{T}$ has a physical meaning also for turbulence studies, and "T gives an indication of the temporal scale of turbulent eddies" [19].

$$
T=\int_{0}^{t} r_{u u}(\Delta t) d t
$$

Fig. 5 shows that the maximum time scale value is calculated to be $0.526 \mathrm{~s}$ for the $\mathrm{u}$ component. According to Yalin, the "largest eddies do not originate in their full size $\approx \mathrm{h}$ (water depth). Rather, they are generated near the flow the smaller is its initial size in comparison to $h$ " [20].

Another important parameter is the integral length scale, which can be obtained from $\mathrm{T}$ for each component of velocity. The integral length scale is an estimate of the average size of the largest eddy in the flow. Hinze [21] states that this can be obtained by multiplying $\mathrm{T}$ by the local mean velocity, as shown in Equation 4. The integral length scales are calculated for point number 64 .

$$
\mathrm{L}=\mathrm{u}^{*} \mathrm{~T}
$$

By multiplying the integral time scale for $\mathrm{x}$ direction, $\mathrm{Tu}=0.526 \mathrm{~s}$ by the local mean velocity $\mathrm{u}=-2.09 \mathrm{~cm} / \mathrm{c}$ $\mathrm{Lu}=1.09 \mathrm{~cm}$ this value is logical because, as seen in Fig. 3, point 64 is downstream of the cylinder in the area of fluctuating wake vortices so that small eddy size is observed. Fig. 6 shows an autocorrelogram of the velocity data at point 46 .

The integral time scales for point 46 are $\mathrm{T}_{\mathrm{u}}=1.375 \mathrm{~s}, \mathrm{~T}_{\mathrm{v}}=0.997 \mathrm{~s}$, and $\mathrm{T}_{\mathrm{w}}=0.930 \mathrm{sec}$. The integral length scales for point 46 are calculated by multipliying the integral time scales by the local velocity values given in Table 1. The approximate size of the circulation parallel to flow direction is $\mathrm{L}_{\mathrm{u}}=20.27 \mathrm{~cm}$, which is comparable to flow depth in the trapezoidal channel: $23.6 \mathrm{~cm}$. The circulation around vertical axes $\mathrm{W}$ is $\mathrm{L}_{\mathrm{v}}=4.80 \mathrm{~cm}$, and for $\mathrm{w}$ components of the

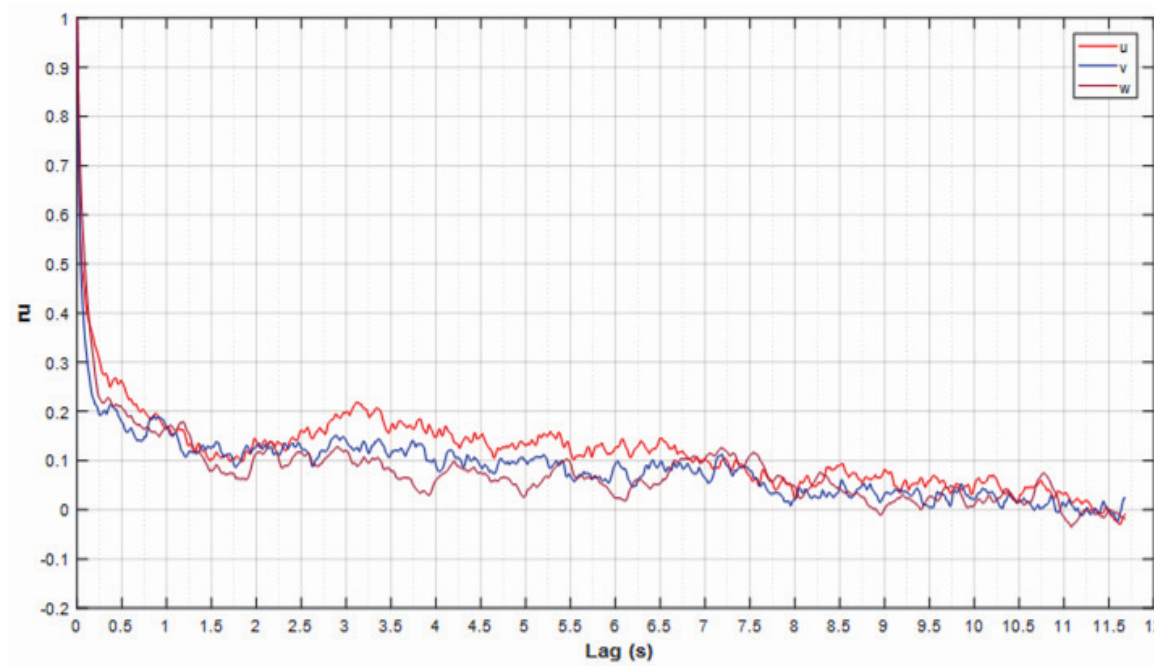

Fig. 6. Autocorrelogram of point 46 for $\mathrm{u}, \mathrm{v}$, and w velocity components. 
fluctuating velocities, circulation in the vertical plane transverse to the flow is $\mathrm{L}_{\mathrm{w}}=2.90 \mathrm{~cm}$. During the discussion process it could be said that to estimate the approximate sizes of eddy sizes rotating around stream vise, transverse and vertical axes, using direct measurement of the mean interval between discrete events is an effective way. Calculated eddy sizes justify that approach.

\section{Spectral Analysis}

Spectral analysis is helpful for displaying the distribution of turbulence kinetic energy (TKE) for each velocity component at different frequencies. In spectral analysis, turbulent fluctuations are assumed as the superposition of the various frequency components. "Energy cascade process in which macro-scale vortices transport the energy to micro-scale vortices dissipate energy" [22]. According to Nikora and Goring [23], "In most open-channel studies, a three-range model of velocity spectra has been accepted, implicitly or explicitly, which consists of 1) the production range where spectra behavior has not been identified specifically; 2) the inertial subrange where autospectra follow the " $-5 / 3$ " law (there is no energy production or dissipation in this subrange and the turbulence energy flows from larger scales to smaller ones until it reaches the viscous range where dissipation occurs); and 3) the viscous range where spectra decay much faster than in the inertial subrange."

In this study data is sampled at $100 \mathrm{~Hz}$. Therefore, the Nyquist frequency is $50 \mathrm{~Hz}$. The maximum sampling capacity of the device is $200 \mathrm{~Hz}$. At very high sampling frequencies very high noise is observed,

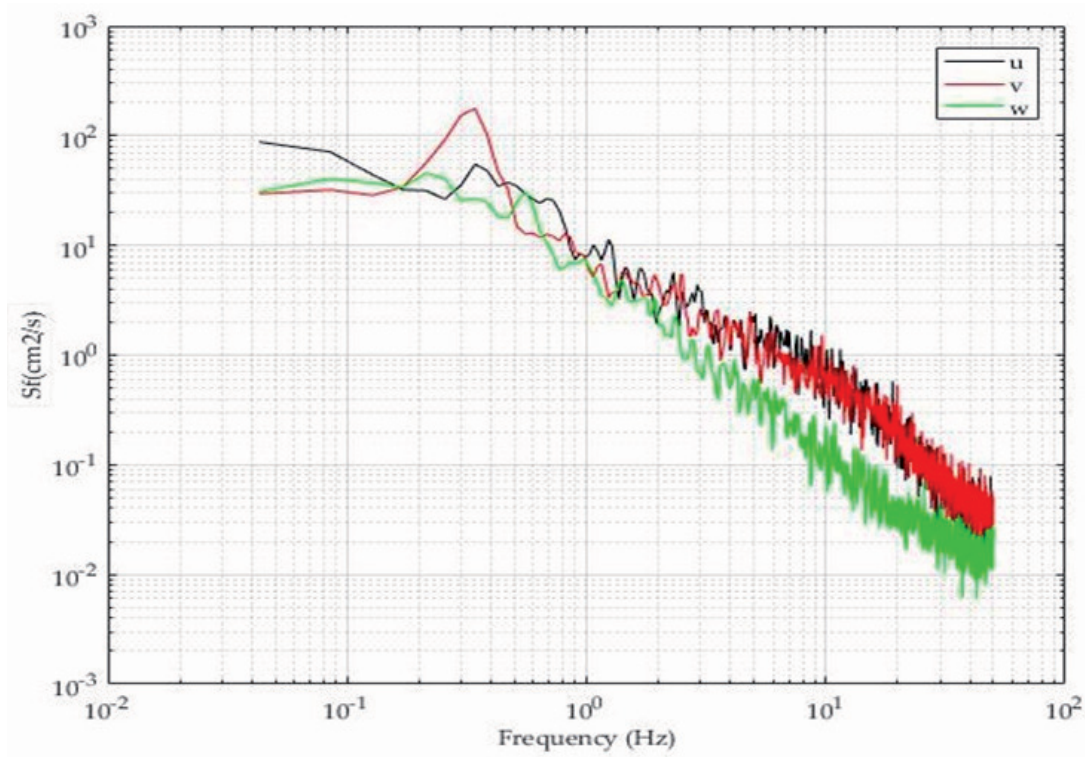

Fig. 7. Power spectral density of point 64 for $\mathrm{x}, \mathrm{y}$, and $\mathrm{z}$ velocity components.

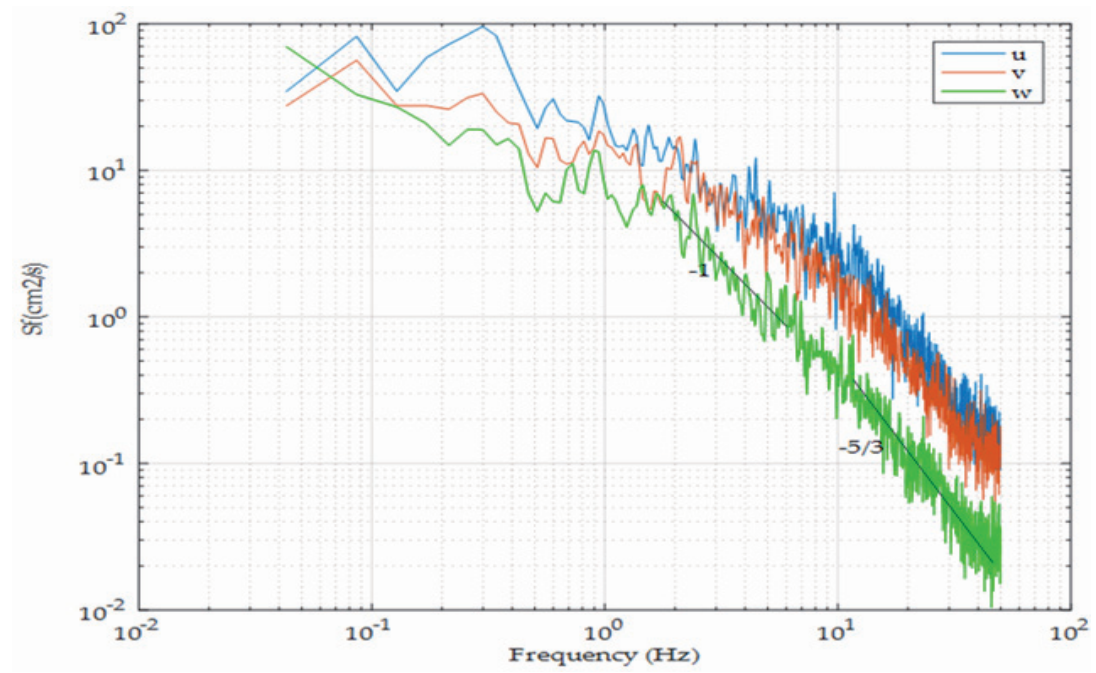

Fig. 8. Power spectral density of point 46 for $\mathrm{x}, \mathrm{y}$, and $\mathrm{z}$ velocity components. 
therefore $100 \mathrm{~Hz}$ is preferred as a sampling frequency. The area under the velocity spectral density function is equal to the total variance for that velocity component. The velocity spectral density distribution for each point and for each velocity component is obtained. Tukey tapering window is used to minimize the error in calculating the spectral density function, which is the Fourier transform of Equation 2.The results are shown in Figs 7-8 for points 64 and 46, respectively.

Figs 7 and 8 show that most of the energy is observed at frequencies in the range of $0-10 \mathrm{~Hz}$; Energy contribution from frequencies greater than $10 \mathrm{~Hz}$ are negligible. In Fig. 8, a -5/3 slope of spectra and inertial sub range regions are clearly observed for $\mathrm{u}, \mathrm{v}$, and $\mathrm{w}$ velocity components.

\section{Conclusions}

The impacts of engineering projects on riverine environment must be investigated in the perspective of circulations and turbulence. Eddies caused by turbulence have an important role on the nutrition transfer and kinematics of fish. Increased turbulence and high turbulent kinetic energy parameters increase the nutrient mixing via fluctuations and circulations. Also, fish kinematics and turbulence interaction has an extra importance in design and construction of fish passes. To better understand the periodic character, dependence, and energy content of the circulations, a model was used in the laboratory to simulate a boulder in the riverine environment - a cylinder placed vertically in the middle of a trapezoidal channel followed by detailed and sensitive measurements. It is believed that such similar studies could be a first step for correct model studies in natural habitat. Turbulence fluctuations of flow velocities around a cylinder were investigated, and the distribution of turbulent velocity fluctuations are given in the table for all close and far points to the cylinder. The turbulent region can be observed as acceleration, separation, and circulation areas. Representative circulation sizes are calculated and given in this study.

1) According to autocorrelation function results, the points close to the wake region is highly dependent. Spectral analysis shows that most of the turbulence kinetic energy is concentrated in high-period (lowfrequency) structures (circulations and eddies).

2) The spectral density plot obtained for point 64 - which is at the mixing line of the wake vortices downstream of and very close to the cylindrical obstacle - shows a chaotic turbulence structure. Therefore the $-5 / 3$ slope is not clearly observed. However, in the spectral density plot obtained from point 46 a slope of -1 is clearly observed before the inertial sub-range slope of $-5 / 3$. In that location vortex shedding is clearly observable.

3) The study also shows that Reynolds stress values are increased rapidly at positions close to the cylinder. Further research on turbulence flow characteristics in a riverine environment will be fruitful for understanding eco hydraulics.

\section{Acknowledgements}

The author is grateful for the postdoctoral support provided by the Scientific and Technological Research Council of Turkey (TUBITAK). I also thank Prof. Ben Hodges at CRWR UT at Austin for permission to use the experimental setup.

\section{References}

1. FRANCA M.J., BROCCHINI M. Turbulence in rivers, in Rivers-Physical, Fluvial and Environmental Processes., Springer. 51, 2015.

2. DAVIDSON P. Turbulence: an introduction for scientists and engineers.: Oxford University Press, 2015.

3. BENNET S., GHANEEIZAD S.M., GALLISDORFER M.S., LANGENDOEN E.J. Flow, turbulence, and drag associated with engineered $\log$ jams in a fixed-bed experimental channel. Geomorphology, 248, 172, 2015.

4. MARUSIC I., MONTY J.P., HULTMARK M., SMITS A.J. On the logarithmic region in wall turbulence. Journal of Fluid Mechanics 716, R3, 2013.

5. BRADSHAW P., An introduction to turbulence and its measurement: thermodynamics and fluid mechanics series.: Elsevier, 2013

6. CONSTANTINESCU G., KOKEN M., ZENG J., The structure of turbulent flow in an open channel bend of strong curvature with deformed bed: Insight provided by detached eddy simulation. Water Resources Research. 47 (5), 2011.

7. BAYKAL C., SUMER B.M., FUHRMAN D.R., JACOBSEN N.G., FREDSOE J. Numerical investigation of flow and scour around a vertical circular cylinder. Philosophical Transactions of the Royal Society of London A: Mathematical, Physical and Engineering Sciences, 373 (2033), 20140104, 2015.

8. CHANG, P.K., Separation of flow.: Elsevier, 2014.

9. WANG X.Y., YANG G.Y., LU W.Z., WANG X.K. Experimental study of near-wall turbulent characteristics in an open-channel with gravel bed using an acoustic Doppler velocimeter. Experiments in fluids 52 (1), 85, 2012

10. BEHESHTI A., ATAIE-ASHTIANI B., Scour hole influence on turbulent flow field around complex bridge piers. Flow, Turbulence and Combustion,. 97 (2), 451, 2016.

11. BAKI A.B.M. Flow Structures in the Vicinity of a Submerged Boulder within a Boulder Array. Journal of Hydraulic Engineering, 04016104, 2016.

12. YILMAZ M., YANMAZ M., KOKEN M. Clear-water scour evolution at dual bridge piers. Canadian Journal of Civil Engineering, (ja), 2017.

13. DOGAN A., Flow around bridge piers in Civil Engineering. Middle East Technical University: Ankara, 1993.

14. MADDOCK, I., HARBY, A. KEMP, P,WOOD, Ecohydraulics: an integrated approach John Wiley \& Sons 2013.

15. TERMINI D. Experimental Analysis of Horizontal Turbulence of Flow over Flat and Deformed Beds. Archives of Hydro-Engineering and Environmental Mechanics. 62 (3-4), 77, 2015. 
16. TIWARI H., SHARMA N. Turbulent kinetic energy in the upstream of Piano Key Weir. Arabian Journal for Science and Engineering. 41 (10), 4147, 2016.

17. GORING D.G., NIKORA V.I. Despiking acoustic Doppler velocimeter data. Journal of Hydraulic Engineering,. 128 (1), 117, 2002.

18. STOER J., BULIRSCH R. Introduction to numerical analysis. Vol. 12.: Springer Science \& Business Media, 2013.

19. MONIN A.S., YAGLOM A.M. Statistical fluid mechanics, volume II: Mechanics of turbulence. Vol. 2.: Courier Corporation, 2013.
20. YALIN M.S. Mechanics of Sediment Transport. Pergamon. and early results. Sediment. Geol. 15, 1, 1972.

21. HINZE J. Turbulence McGraw-Hill. New York, 2181975.

22. KUCUKALI S., HASSINGER R. Flow and turbulence structure in a baffle-brush fish pass. in Proceedings of the Institution of Civil Engineers-Water Management.https:// doi.org/10.1680/wama.16.00024 Published online October 31, 2016.

23. NIKORA V., GORING D. Flow turbulence over fixed and weakly mobile gravel beds. Journal of Hydraulic Engineering. 126 (9), 679, 2000. 